\title{
SLC26A3 inhibitor identified in small molecule screen blocks colonic fluid absorption and reduces constipation
}

\author{
Peter M. Haggie, ${ }^{1}$ Onur Cil,, ${ }^{1,2}$ Sujin Lee, ${ }^{1}$ Joseph-Anthony Tan, ${ }^{1}$ Amber A. Rivera, ${ }^{1}$ Puay-Wah Phuan, ${ }^{1}$ \\ and Alan S. Verkman ${ }^{1,3}$ \\ 'Department of Medicine, 2Department of Pediatrics, and ${ }^{3}$ Department of Physiology, UCSF, San Francisco, California, USA.
}

\begin{abstract}
SLC26A3 (downregulated in adenoma; DRA) is a $\mathrm{Cl}^{-}$/anion exchanger expressed in the luminal membrane of intestinal epithelial cells, where it facilitates electroneutral $\mathrm{NaCl}$ absorption. SLC26A3 loss of function in humans or mice causes chloride-losing diarrhea. Here, we identified slc26a3 inhibitors in a screen of 50,000 synthetic small molecules done in Fischer rat thyroid (FRT) cells coexpressing sIc26a3 and a genetically encoded halide sensor. Structure-activity relationship studies were done on the most potent inhibitor classes identified in the screen: 4,8-dimethylcoumarins and acetamide-thioimidazoles. The dimethylcoumarin $D_{R A} A_{i n h}-A 250$ fully and reversibly inhibited slc26a3-mediated $\mathrm{Cl}^{-}$exchange with $\mathrm{HCO}_{3}{ }^{-}, \mathrm{I}^{-}$, and thiocyanate ( $\mathrm{SCN}^{-}$), with an IC $\mathrm{I}_{50}$ of $\sim 0.2 \mu \mathrm{M}$. DRA ${ }_{\text {inh }}-\mathrm{A} 250$ did not inhibit the homologous anion exchangers slc26a4 (pendrin) or slc26a6 (PAT-1), nor did it alter activity of other related proteins or intestinal ion channels. In mice, intraluminal DRA ${ }_{\text {inh }}$-A250 blocked fluid absorption in closed colonic loops but not in jejunal loops, while the NHE3 (SLC9A3) inhibitor tenapanor blocked absorption only in the jejunum. Oral $D_{\text {DRh }}$-A250 and tenapanor comparably reduced signs of constipation in loperamide-treated mice, with additive effects found on coadministration. DRA ${ }_{\text {inh }}-A 250$ was also effective in loperamidetreated cystic fibrosis mice. These studies support a major role of slc26a3 in colonic fluid absorption and suggest the therapeutic utility of SLC26A3 inhibition in constipation.
\end{abstract}

Conflict of interest: The authors have declared that no conflict of interest exists.

Submitted: March 28, 2018

Accepted: June 12, 2018

Published: July 25, 2018

\section{Reference information:} JCI Insight. 2018;3(14):e121370. https://doi.org/10.1172/jici. insight.121370.

\section{Introduction}

SLC26A3, originally named downregulated in adenoma (DRA), is an anion exchanger expressed at the lumen-facing plasma membrane of enterocytes in the colon and small intestine (1-4). SLC26A3 facilitates exchange of various monovalent anions, including $\mathrm{Cl}^{-}, \mathrm{HCO}_{3}^{-}$, and thiocyanate $\left(\mathrm{SCN}^{-}\right)$, as well as the divalent anion oxalate (5-9). SLC26A3-mediated $\mathrm{Cl}^{-} / \mathrm{HCO}_{3}^{-}$exchange is involved in electroneutral $\mathrm{NaCl}$ absorption, which drives water absorption in the colon and small intestine (4, 8, 10-14). Loss-of-function mutations in SLC26A3 cause congenital chloride-losing diarrhea (CLD) in humans, which is characterized by severe diarrhea that starts in utero $(15,16)$. In mice, knock-out $(\mathrm{KO})$ of slc26a3 recapitulates CLD, producing diarrhea and metabolic alkalosis (10). SLC26A3 inhibition is, thus, a potential approach to treat constipation by blocking intestinal fluid absorption, which may be effective in the major types of constipation, including opioid-induced constipation (OIC), and in constipation associated with cystic fibrosis (CF) in which the pro-secretory CFTR $\mathrm{Cl}^{-}$channel is defective (17).

SLC26A3 is a member of the SLC26 gene family of anion channels and transporters. The closest SLC26A3 homolog, SLC26A4 (pendrin; 45\% amino acid identity), is an anion exchanger in the inner ear, thyroid, inflamed airways, and kidney $(6,9,18)$. We previously identified small-molecule pendrin inhibitors that increased airway surface liquid depth in airway epithelial cell cultures and produced a diuretic response in mice, suggesting potential therapeutic utility in inflammatory lung disorders, such as CF and asthma, and in volume-overload edema $(19,20)$. The second most closely related SLC26A3 homolog, SLC26A6 (putative anion transporter-1 [PAT-1]; 34\% amino acid identity), is also an anion exchanger expressed at the apical membrane in the small intestine that, together with SLC26A3, facilitates electroneutral $\mathrm{NaCl}$ absorption $(21,22)$.

We report here the identification, by high-throughput screening, of nanomolar-potency small molecule SLC26A3 inhibitors, their optimization by structure-activity analysis, and their characterization in cellular models. Inhibition of intestinal fluid absorption was demonstrated in closed intestinal loops in mice, and 
A

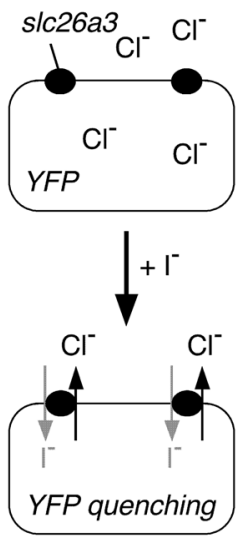

B

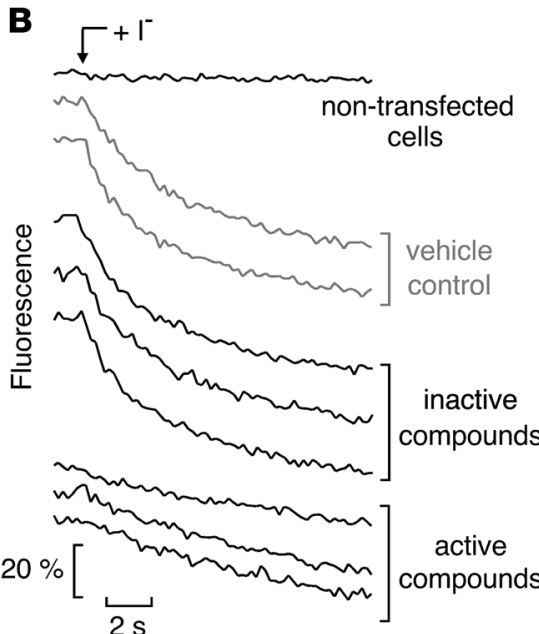

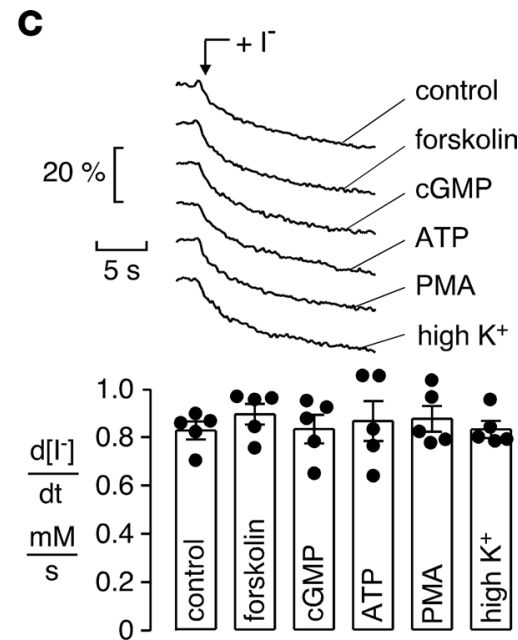

Figure 1. Assay for high-throughput identification of SLC26A3 inhibitors. (A) Assay schematic. Extracellular addition of an $\mathrm{I}^{-}$-containing solution drives slc26a3-mediated $\mathrm{Cl}^{-} / \mathrm{I}^{-}$exchange, resulting in YFP fluorescence quenching. (B) Representative fluorescence time course data for nontransfected cells, and slc26a3-transfected cells for vehicle control and inactive and active compounds. (C) Absence of slc26a3 regulation by common second messengers, and membrane depolarization. Fluorescence time course data (top) and summary (bottom) for slc26a-mediated $\mathrm{Cl}^{-} / \mathrm{I}^{-}$exchange under control conditions and after cell treatments to activate $\mathrm{CAMP}, \mathrm{CGMP}, \mathrm{Ca}^{2+}$, or phorbol ester signaling, or depolarization (mean $\pm \mathrm{SEM}, n=5$, differences not significant by one-way ANOVA).

efficacy was demonstrated in an experimental model of constipation. Inhibition of slc26a3 reduced manifestations of constipation with comparable efficicacy to a blocker of intestinal $\mathrm{Na}^{+}$absorption, the NHE3 inhibitor tenapanor, and when coadministered, slc26a 3 and NHE3 inhibitors fully reversed constipation.

\section{Results}

High-throughput screen to identify slc26a3 inhibitors. Screening was done using a Fischer rat thyroid (FRT) cell line stably expressing murine slc26a3 and a halide-sensitive yellow fluorescent protein (FRT-YFP-slc26a3 cells). FRT cells were used because of their low intrinsic permeability to anions that are transported by slc26a 3 and because of their good adherence and rapid growth on uncoated plastic. As diagrammed in Figure 1A, slc26a3-mediated transport was assayed from the kinetics of YFP fluorescence quenching in response to extracellular addition of $\mathrm{I}^{-}$to drive the $\mathrm{Cl}^{-} / \mathrm{I}^{-}$exchange; transport inhibition reduces the rate of fluorescence decrease. Figure 1B shows representative fluorescence data from inactive and active compounds tested in screening, together with data from vehicle (DMSO) control and cells not expressing slc26a3. For screening, the nonselective chloride channel blocker niflumic acid was used as a positive control, which strongly inhibited slc26a 3 at $350 \mu \mathrm{M}$. The Z-factor for the slc26a3 screening assay was $\sim 0.7$.

To test whether second messengers regulate slc26a3 activity in the transfected FRT cells, experiments were done in which FRT-YFP-slc26a 3 cells were preincubated with forskolin $(20 \mu \mathrm{M}$; to elevate cAMP), 8-bromoguanosine 3',5'-cyclic monophosphate (100 $\mu \mathrm{M}$; 8-Br-cGMP; a cell permeable cGMP analog), ATP (100 $\mu \mathrm{M}$; to elevate cytoplasmic $\left.\mathrm{Ca}^{2+}\right)$, phorbol 12-myristate 13-acetate (100 nM; PMA), or $20 \mathrm{mM}$ potassium chloride (high $\mathrm{K}^{+}$; to depolarize membrane potential). None of these maneuvers significantly altered electroneutral slc26a3-mediated $\mathrm{Cl}^{-} / \mathrm{I}^{-}$exchange (Figure 1C). Therefore, inhibitors identified in the screen are likely to inhibit slc26a3 exchange directly rather than acting on upstream signaling mechanisms.

Screening of 50,000 synthetic small molecules at $25 \mu \mathrm{M}$ identified 136 active compounds that inhibited slc $26 \mathrm{a} 3$ by $>75 \%$. The compounds clustered in several compound classes, including 4,8 -dimethylcoumarins, acetamide-thioimidazoles, triazoleamides, and thiazole-thiophenesulphonamides (Classes A-D, respectively) (Figure 2, A and B). A scatter plot of inhibition percentage for a subset of screened compounds, shown in the order as screened (Figure 2A, left), revealed clusters of active compounds as a consequence of grouping of chemical scaffolds in compound plates. On retesting, 36 compounds inhibited slc26a3 by more than $50 \%$ at $10 \mu \mathrm{M}$ (Figure 2A, right), including multiple Class A and Class B compounds. 
A

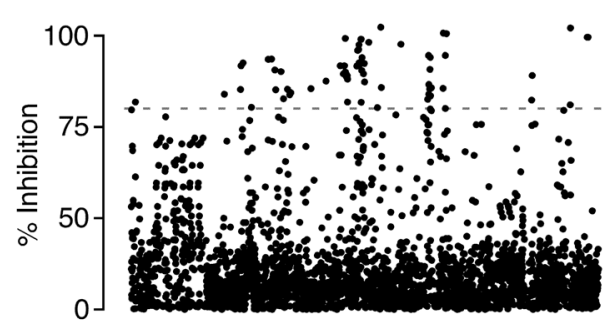

B<smiles>Cc1c(CC(=O)O)c(=O)oc2c(C)c(OCc3ccccc3)ccc12</smiles><smiles>O=C(CSc1nccn1-c1ccc(F)cc1)Nc1ccc(Br)cc1</smiles><smiles>O=C(Nc1ccc2c(c1)OCCO2)c1nn[nH]c1Nc1ccccc1Cl</smiles>

$\mathrm{DRA}_{\mathrm{inh}}-\mathrm{C01}$<smiles>CCc1csc(-c2ccc(S(=O)(=O)Nc3cccc(C)c3F)s2)n1</smiles>

$\mathrm{DRA}_{\mathrm{inh}}-\mathrm{D} 01$

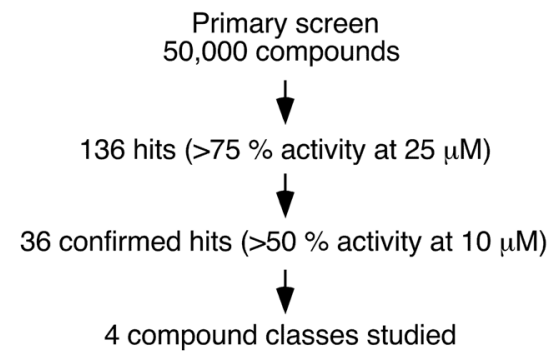

C

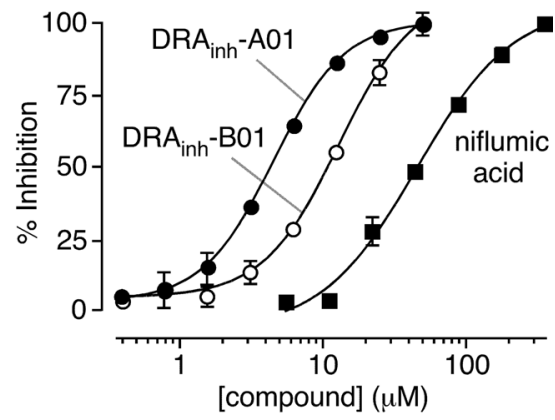

Figure 2. Murine sIc26a3 inhibitors identified by high-throughput screening. (A) Left panel: dot plot of primary screen data for 18,000 compounds at $25 \mu \mathrm{M}$ showing percentage inhibition. Right panel: summary of results from screen. (B) Structures of active compounds of 4 chemical classes identified in the primary screen. (C) Concentration-dependence of slc26a3 inhibition for a Class A and a Class B compound identified in screening, and niflumic acid (mean \pm SEM, $n=6$ ). Fitted curves for a single-site inhibition model.

Figure $2 \mathrm{C}$ shows concentration-dependence measurements for inhibition of slc26a3-mediated $\mathrm{Cl}^{-} / \mathrm{I}^{-}$ exchange for a selected Class $\mathrm{A}\left(\mathrm{IC}_{50} \sim 4 \mu \mathrm{M}\right)$ and Class $\mathrm{B}\left(\mathrm{IC}_{50} \sim 9 \mu \mathrm{M}\right)$ compound discovered in the primary screen, together with data for niflumic acid $\left(\mathrm{IC}_{50} \sim 60 \mu \mathrm{M}\right)$.

Structure-activity relationship studies. Based on potency data and structural considerations, compounds of Classes A and B were prioritized for further study. A total of 176 commercially available Class A analogs and 175 Class B analogs were tested. Figure 3, A and B, summarizes the structural determinants of activity for Class A and Class B compounds (left panels), with concentration-dependence data of selected analogs provided (right panels). Class A compounds are coumarins that are substituted with methyl group on the 4 and 8 positions. Structure-activity analysis showed that the acetic acid moiety at the 3 position $\left(\mathrm{R}^{2}\right)$ is required for activity, as the corresponding acetate ester was inactive. Replacement of the acetic acid with propanoic acid greatly reduced activity, and nonacid substituents including alkyl and benzyl were inactive. Greatest potency was found for hydroxylation at the 7 position on the coumarin with a benzyl ring $\left(\mathrm{R}^{1}\right)$, with 3-chloro, 3-fluoro, and 3-bromo substituents giving greatest potency.

Class B compounds are acetamide-thioimidazoles with substituents on the imidazole $\left(\mathrm{R}^{1}\right)$ ring and acetamide linker $\left(\mathrm{R}^{2}\right)$. For the $\mathrm{R}^{1}$ group, phenyl gave the best activity, with benzofuran, benzyl, methyl, and acetate reducing activity. Unsubstituted phenyl gave the greatest potency, although 4-methoxy and 4-chloro were also active, while substituents on the 2 position reduced activity. For $\mathrm{R}^{2}$, several substituted anilines were active, whereas nonaniline, alkyl, benzyl and allyl groups reduced activity. Anilines substituted with 3-chloro-4-methyl were most active. Other substituents on the aniline ring — including 4-halide, 4-methyl, and 4-methoxy - were active. In general, 3,4-disubstituted and 4-substituted anilines with electron neutral or donating groups were best, whereas $4-\mathrm{NO}_{2}$ and 3,4-disubstituted anilines with electron-withdrawing groups reduced activity.

Supplemental Tables 1 and 2 (supplemental material available online with this article; https://doi. org/10.1172/jci.insight.121370DS1) list $\mathrm{IC}_{50}$ values for selected active Class A and Class B compounds, respectively. $\mathrm{DRA}_{\mathrm{inh}}$-A250 was the most potent Class A compound with an $\mathrm{IC}_{50}$ of $0.15 \mu \mathrm{M}$ (Figure $3 \mathrm{~A}$, right panel). Several other Class A analogs were also found to be more potent than $\mathrm{DRA}_{\mathrm{inh}}-\mathrm{A} 01$, the original compound identified in the primary screen. For Class B, a number of analogs showed greater potency 
A<smiles>[Y]c1cccc(CC(C)C)c1</smiles>
Best X: 3-Br, 3-Cl, 3-F, 3-Me

Moderate X: 3-OMe, 2-F, 3,5$\mathrm{Me}, 3,4-\mathrm{Cl}, 4-\mathrm{F}$

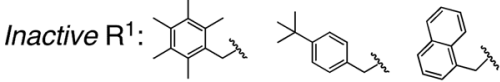
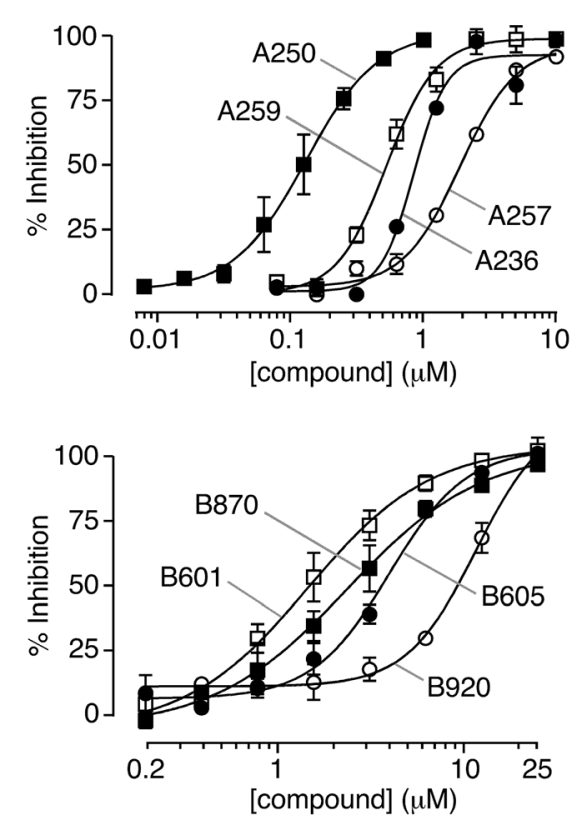

B

Best $\mathrm{R}^{1}$ :

Best X: $\mathrm{H}, 3,4-\mathrm{Cl}, 4-\mathrm{Br}$, 3-Cl-4-Me, 4-Cl, 4- $\mathrm{MeO}, 3,5-\mathrm{Me}$

Moderate X: 3-Me, 2,3-Me, 3-OMe
Best $\mathrm{R}^{2}:$ s 4-Br, 4-Cl, 4-Me, 4-MeO

Inactive $\mathrm{X}: 4-\mathrm{NO}_{2}, 3,4-\mathrm{Cl}$, Inactive $\mathrm{R}^{2}$ : $\mathrm{Me}, \mathrm{Et}$

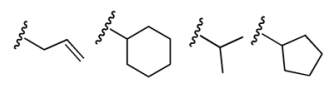

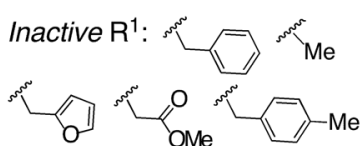

Best $\mathrm{R}^{2}:$ s $\mathrm{O}_{\mathrm{OH}}>$ 乡

Inactive $\mathrm{R}^{2}$ :

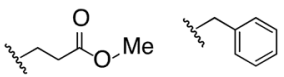

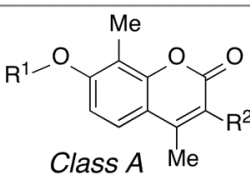

然 $\mathrm{Me}$ 合

C

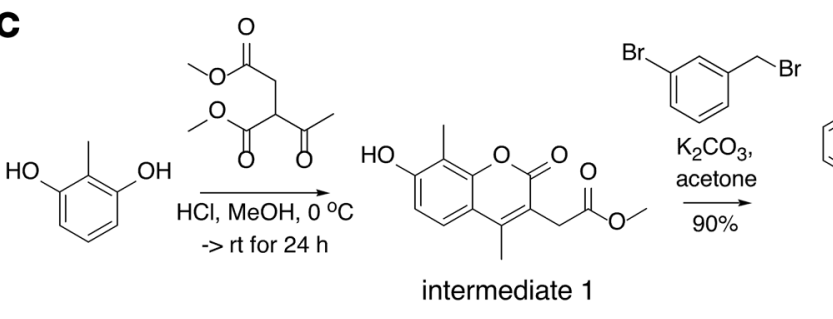

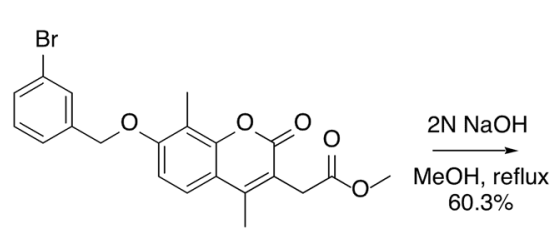

intermediate 2

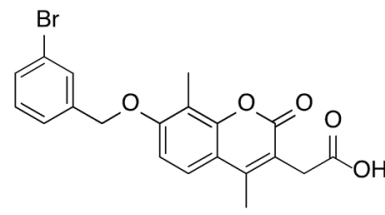

DRA $_{\text {inh }}-\mathrm{A} 250$

Figure 3. Structure-activity relationships for Class A and Class B slc26a3 inhibitors. (A) Class A. Left panel: core structure of the Class A inhibitor is boxed; active and inactive substituents are listed. Right panel: concentration-dependence measurements for selected Class $A$ compounds, including $\mathrm{DRA}_{\text {inh }}-\mathrm{A} 250$ (mean $\pm \mathrm{SEM}, n=3$ ). (B) Class B, showing core structure (boxed) with active and inactive substituents (left panel) and concentration-dependence measurements (right panel; mean $\pm \mathrm{SEM}, n=3$ ). (C) Route for synthesis of $D R A_{\text {inh }}-\mathrm{A}_{250}$.

than the original active compound ( $\left.\mathrm{DRA}_{\mathrm{inh}}-\mathrm{B} 01, \mathrm{IC}_{50} \sim 9 \mu \mathrm{M}\right)$, with $\mathrm{DRA}_{\mathrm{inh}}-\mathrm{B} 601$ having the lowest $\mathrm{IC}_{50}$ $(\sim 1.5 \mu \mathrm{M}$; Figure 3B, right panel).

For further studies, DRA inh -A250 was resynthesized (Figure 3C) by Pechmann condensation of 2-methylresorcinol with dimethyl acetylsuccinate to yield 7-hydroxycoumarin (intermediate 1), which was further alkylated with 3-bromobenzyl bromide to give coumarin ester (intermediate 2) (23, 24). Hydrolysis of the coumarin ester gave the corresponding 3-acetic acid-coumarin $\mathrm{DRA}_{\mathrm{inh}}-\mathrm{A} 250$ in good yield (Figure $3 C$ ).

$D R A_{\text {inh }}$-A250 characterization. Concentration-dependence measurements for inhibition of the slc26a3-mediated exchange of $\mathrm{Cl}^{-}$and $\mathrm{HCO}_{3}^{-}$, the physiologically relevant activity of slc26a3, was measured using slc26a3-expressing FRT cells labeled with BCECF as a cytoplasmic $\mathrm{pH}$ sensor. Labeled cells were initially incubated in a $\mathrm{Cl}^{-}$-containing $\mathrm{HCO}_{3}^{-}$buffered solution, and $\mathrm{HCO}_{3}^{-}$influx $/ \mathrm{Cl}^{-}$efflux with cytoplasmic alkalinization was produced by addition of a gluconate-containing $\mathrm{HCO}_{3}^{-}$buffered solution. The increase in cytoplasmic $\mathrm{pH}\left(\sim 0.05 \mathrm{pH}\right.$ units/min) was inhibited by $\mathrm{DRA}_{\text {inh }}$-A250 with $\mathrm{IC}_{50} \sim 0.1$ $\mu \mathrm{M}$ (Figure 4A). Concentration-dependence measurements for inhibition of slc26a3-mediated $\mathrm{Cl}^{-} / \mathrm{SCN}^{-}$ exchange gave an $\mathrm{IC}_{50}$ of $\sim 0.3 \mu \mathrm{M}$ (Figure $4 \mathrm{~B}$ ). The kinetics of $\mathrm{DRA}_{\mathrm{inh}}$-A250 inhibition, measured by incubation of FRT-YFP-slc26a3 cells with $1 \mu \mathrm{M} \mathrm{DRA}_{\text {inh }}$-A250 for different times prior to initiation of the $\mathrm{Cl}^{-} / \mathrm{I}^{-}$exchange, showed a half-time $\left(\mathrm{t}_{1 / 2}\right)$ for inhibition of $\sim 30$ seconds (Figure $4 \mathrm{C}$ ). To confirm full reversibility, FRT-YFP-slc26a3 cells were incubated with $1 \mu \mathrm{M} \mathrm{DRA}_{\mathrm{inh}}-\mathrm{A} 250$ for 10 minutes and then washed 3 times prior to assay $\mathrm{Cl}^{-} / \mathrm{I}^{-}$exchange (Figure $4 \mathrm{C}$, inset). Inhibition of (human) SLC26A3 by $\mathrm{DRA}_{\text {inh }}$-A250 was also tested, using a HEK cell model expressing SLC26A3 and YFP. SLC26A3-mediated $\mathrm{Cl}^{-} / \mathrm{I}^{-}$exchange was inhibited by $\mathrm{DRA}_{\mathrm{inh}}-\mathrm{A} 250$ with $\mathrm{IC}_{50} \sim 0.25 \mu \mathrm{M}$, with complete inhibition at higher $\mathrm{DRA}_{\text {inh }}-\mathrm{A} 250$ concentrations (Figure 4D). 

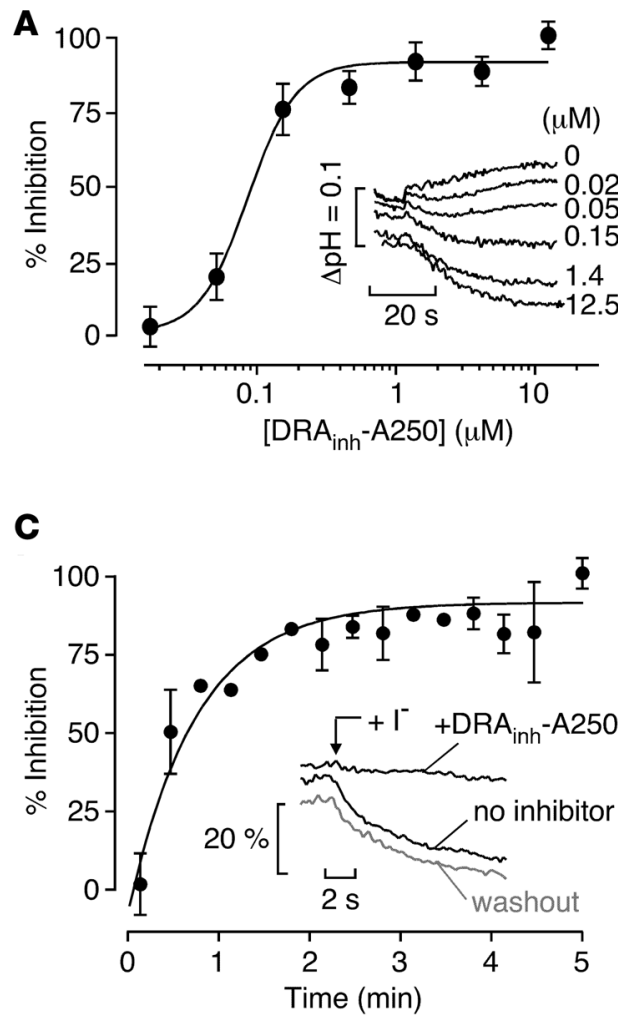

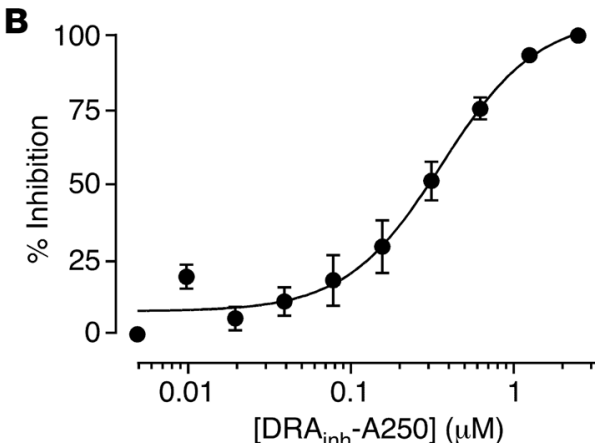

D

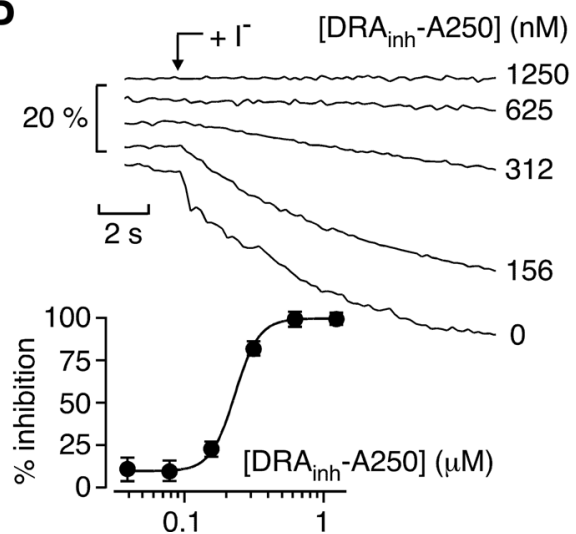

Figure 4. Characterization of DRA inh $^{-A 250}$ action. (A) Concentration dependence of $D R A_{\text {inh }}-A 250$ inhibition of slc26a3-mediated $\mathrm{Cl}^{-} / \mathrm{HCO}_{3}{ }^{-}$exchange (mean $\pm \mathrm{SEM}, n=6$ ). Inset: original BCECF fluorescence curves for $\mathrm{Cl}^{-} / \mathrm{HCO}_{3}^{-}$ exchange. (B) Concentration dependence of DRA ${ }_{\text {inh }}-\mathrm{A} 250$ inhibition of slc26a3-mediated $\mathrm{Cl}^{-} / \mathrm{SCN}^{-}$exchange (mean \pm SEM, $n=6)$. (C) Time course of DRA ${ }_{\text {inh }}-\mathrm{A} 250(1 \mu \mathrm{M})$ inhibition of slc26a3-mediated $\mathrm{Cl}^{-} / \mathrm{I}^{-}$exchange (mean $\pm \mathrm{SEM}, n=$ 4). Inset: reversibility of $D_{R A} A_{\text {inh }}-A 250(1 \mu \mathrm{M})$ inhibition of slc26a3-mediated $\mathrm{Cl}^{-} / \mathrm{I}^{-}$exchange (data representative of 4 replicates). (D) Inhibition of (human) SLC26A3-mediated $\mathrm{Cl}^{-} / \mathrm{I}^{-}$exchange in HEK cells. YFP fluorescence traces (top) and summary data (mean \pm SEM, $n=12-26$ individual cells analyzed) (bottom)

$D R A_{\text {inh }}$-A250 selectivity. To investigate $\mathrm{DRA}_{\text {inh }}$ - $\mathrm{A} 250$ selectivity, transport assays (full experimental details in Supplemental Methods) were done on a panel of SLC26-family homologs and other relevant epithelial ion transporters and channels. Preincubation of cells with $\mathrm{DRA}_{\mathrm{inh}}-\mathrm{A} 250$ at $10 \mu \mathrm{M}$ did not alter $\mathrm{Cl}^{-} / \mathrm{I}^{-}$-exchange activity of (murine) pendrin (slc26a4), PAT-1 (slc26a6), or slc26a9, as shown in original fluorescence time course data (Figure $5 \mathrm{~A}$ ) and summary data (Figure 5B). DRA $\mathrm{inh}_{\mathrm{A}}-\mathrm{A} 250$ at $10 \mu \mathrm{M}$ also did not alter the activity of the $\mathrm{Cl}^{-}$channels CFTR and TMEM16A. In separate studies, to investigate possible action of $\mathrm{DRA}_{\mathrm{inh}}$-A250 on multiple ion transporters and channels in a human epithelium, human bronchial epithelial (HBE) cells were studied by short-circuit current $\left(\mathrm{I}_{\mathrm{sc}}\right)$, with successive additions of amiloride (to block the epithelial sodium channel; ENaC), forskolin, $\mathrm{CFTR}_{\text {inh }}-172$ (to block CFTR), and ATP (to activate the $\mathrm{Ca}^{2+}$-activated chloride channel; $\mathrm{CaCC}$ ) (Figure 5C). Pretreatment for 20 minutes with 10 $\mu \mathrm{M} \mathrm{DRA}_{\text {inh }}-\mathrm{A} 250$ did not alter $\mathrm{I}_{\mathrm{sc}}$ responses, indicating that $\mathrm{DRA}_{\mathrm{inh}}-\mathrm{A} 250$ did not affect ENaC, CFTR, or $\mathrm{CaCC}$ activity, or the activity of other transporters - including $\mathrm{K}^{+}$channels and the $\mathrm{Na}-\mathrm{K}-\mathrm{Cl}$ cotransporter $\mathrm{NKCC} 1$ - that are required to support their activity. In a preliminary toxicity study, incubation of T84 cells with $10 \mu \mathrm{M} \mathrm{DRA}_{\text {inh }}$-A250 for 24 hours did not cause toxicity (Supplemental Figure 2).

$D R A_{\text {inh }}-250$ inhibits fluid absorption in the distal colon in mice. Closed intestinal loop studies in mice were done to study effects of DRA $\mathrm{inh}_{\mathrm{inh}}$-A250 on fluid absorption. DRA $\mathrm{inh}_{\mathrm{in}}$-A250 administration directly in isolated distal colonic loops completely prevented the reduction in the loop weight/length ratio at 60 minutes, a direct measure of fluid absorption (Figure 6A, top panel). Changes in luminal pH were also determined as a semiquantitative measure of slc26a3-facilitated $\mathrm{HCO}_{3}^{-}$secretion $/ \mathrm{Cl}^{-}$absorption, with slc26a3 inhibition predicted to reduce luminal fluid alkalinization. For these experiments, a phosphate-buffered solution (PBS) without $\mathrm{HCO}_{3}^{-} / \mathrm{CO}_{2}$ was used to avoid confounding effects of luminal carbonic anhydrases. DRA inh -A250 reduced alkalinization of luminal fluid in the distal colonic loops 
A

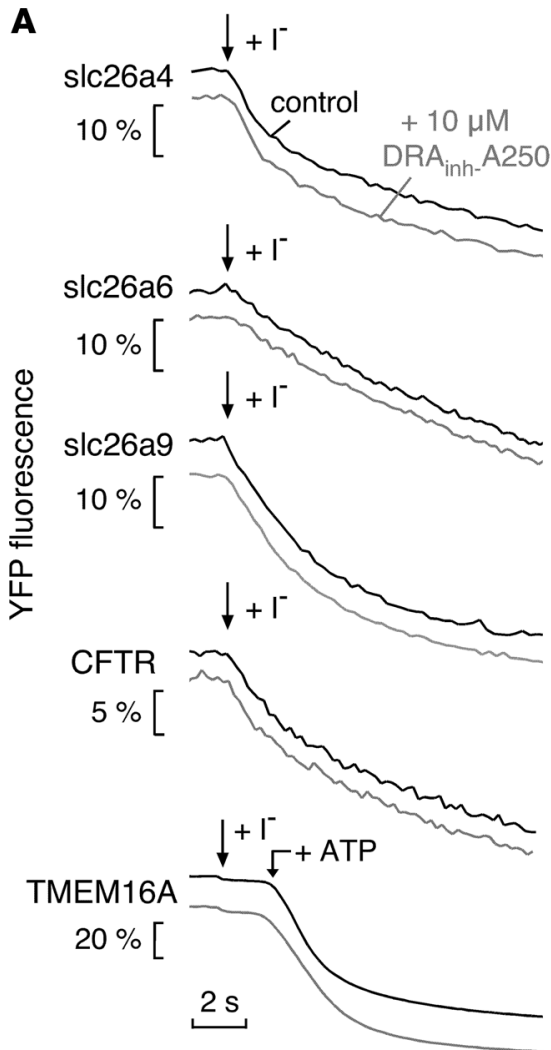

B

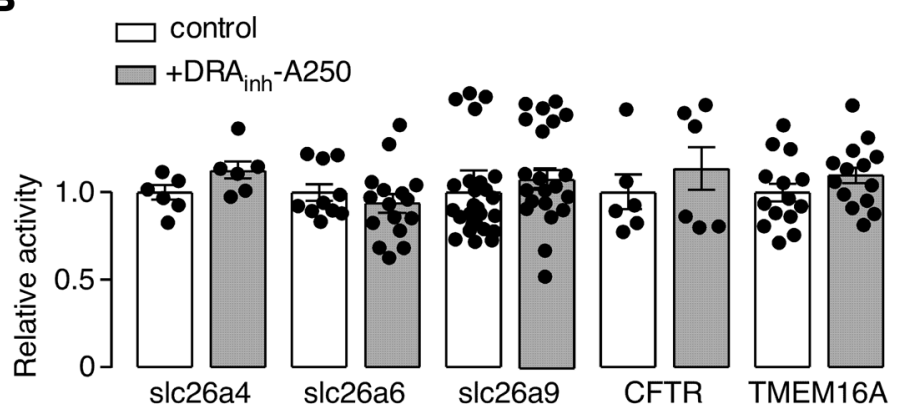

C

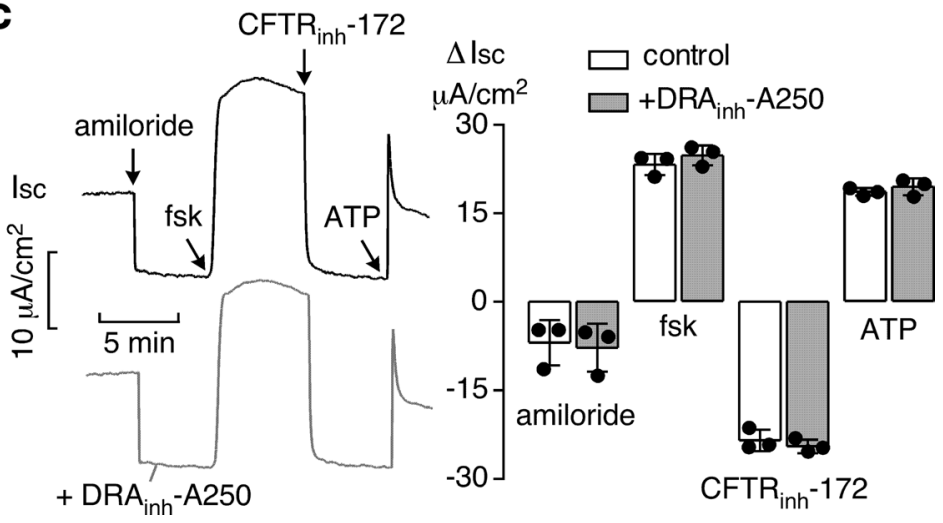

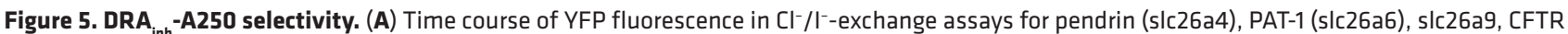
(forskolin [fsk] stimulated), and TMEM16A (ATP-stimulated) in the absence (black lines) and presence (gray lines) of 10 $\mu$ M DRA inh $^{-A 250 . ~ S e e ~ M e t h o d s ~ f o r ~}$ assay details. (B) Summary data for studies as in A with data normalized to control conditions (white bars) (mean \pm SEM, $n=6$ for plate reader assays, and $n=10-28$ for single cell assays, differences not significant by two-tailed $t$ test). (C)Left panel: short-circuit current ( $\left.I_{\text {sc }}\right)$ in well-differentiated HBE cells grown at an air-liquid interface. Studies done in the absence (black traces) and presence (gray traces) of $10 \mu M$ DRA $\mathrm{inh}-\mathrm{A}_{250}$. Where indicated, amiloride $(20 \mu \mathrm{M})$, forskolin $(20 \mu \mathrm{M})$, CFTR $_{\text {in }}-172(10 \mu \mathrm{M})$, and ATP $(100 \mu \mathrm{M})$ were added. Right panel: changes in I for modulator additions (mean \pm SEM, $n=3$, differences not significant by two-tailed $t$ test).

at 60 minutes, consistent with inhibition of $\mathrm{Cl}^{-} / \mathrm{HCO}_{3}^{-}$exchange (Figure $6 \mathrm{~A}$, bottom panel). Administration of the NHE3 $\left(\mathrm{Na}^{+} / \mathrm{H}^{+}\right.$exchanger 3) inhibitor tenapanor (25) had no effect on the weight/ length ratio or luminal $\mathrm{pH}$ in distal colonic loops. Results with coadministration of $\mathrm{DRA}_{\mathrm{inh}}-\mathrm{A} 250$ and tenapanor were similar to those with $\mathrm{DRA}_{\text {inh }}-\mathrm{A} 250$ alone. These results support the conclusion that slc26a3 is the predominant proabsorptive transporter in murine distal colon, whereas NHE3 does not contribute significantly to fluid absorption in this segment.

$D R A_{\text {inh }}$-A250 does not alter jejunal fluid absorption in mice. Administration of $\mathrm{DRA}_{\text {inh }}-\mathrm{A} 250$ to midjejunal loops did not produce significant changes in the loop weight/length ratio, whereas fluid absorption was abolished in tenapanor-treated loops (Figure 6B, top panel). DRA inh $_{\text {in }}-\mathrm{A} 250$ did not alter acidification of jejunal fluid at 30 minutes, with tenapanor preventing acidification and producing slight alkalinization (Figure $6 \mathrm{~B}$, bottom panel). Loops coadministered $\mathrm{DRA}_{\mathrm{inh}}-\mathrm{A} 250$ and tenapanor showed a loop weight/length ratio and luminal fluid $\mathrm{pH}$ that were similar to treatment with tenapanor alone. These results provide evidence against a significant role of slc26a 3 in fluid absorption in mouse jejunum and support the conclusion that NHE3 is a predominant proabsorptive transporter in this segment.

$D R A_{\text {inh }}-A 250$ reduces loperamide-induced constipation in $W T$ and $C F$ mice. Orally administered $\mathrm{DRA}_{\text {inh }}-\mathrm{A} 250$ at $5 \mathrm{mg} / \mathrm{kg}$ partially prevented the loperamide-induced reduction in stool weight, pellet number, and water content in WT mice (Figure 7, A and B). Tenapanor given orally at $5 \mathrm{mg} /$ $\mathrm{kg}$ also partially prevented loperamide-induced reduction in stool weight, pellet number, and water content. The magnitude of these responses is similar to that seen with very high doses of the approved drug linaclotide $(26,27)$. Remarkably, coadministration $\mathrm{DRA}_{\text {inh }}-\mathrm{A} 250$ and tenapanor completely prevented loperamide-induced constipation, suggesting an additive effect of slc26a 3 and NHE3 inhibition 
A
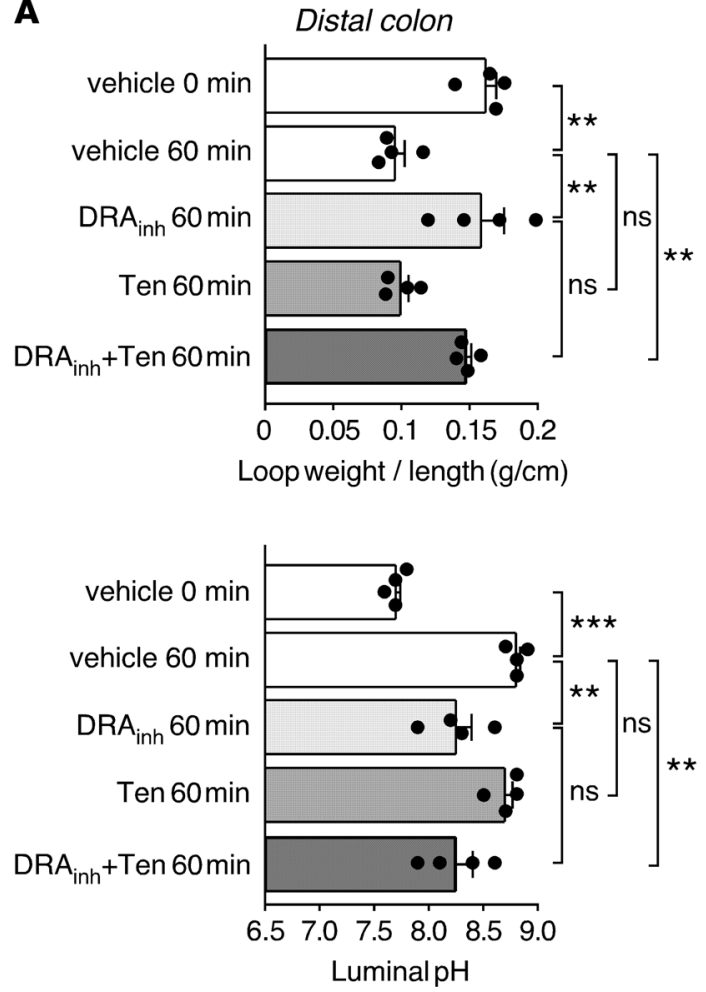

B
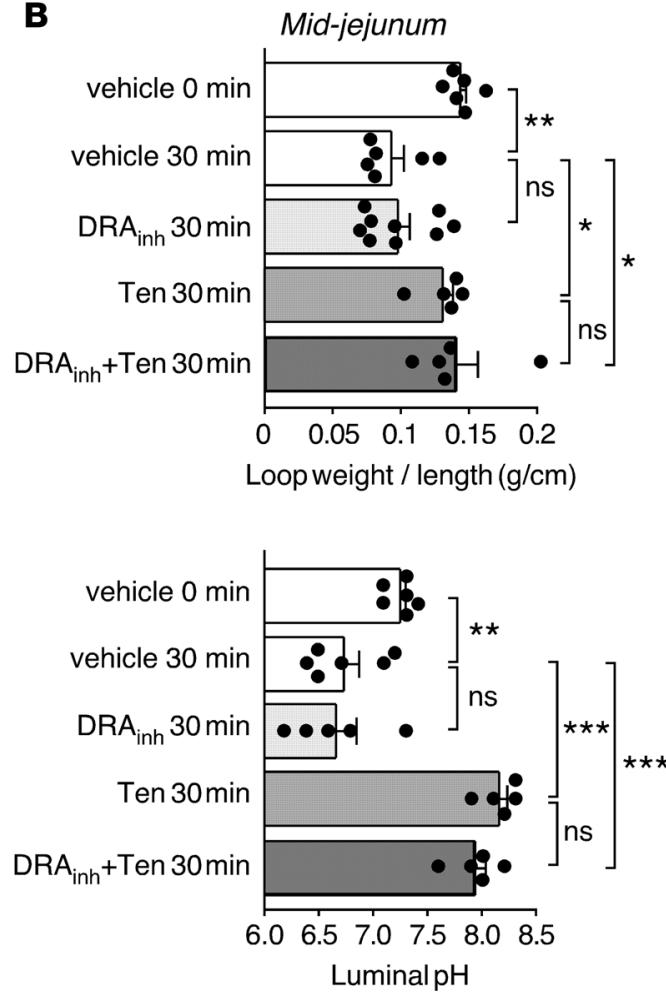

Figure 6. DRA ${ }_{\text {inh }}$-A250 inhibits intestinal fluid absorption in mouse distal colon but not in jejunum. (A) Effects of $\mathrm{DRA}_{\text {inh }}-\mathrm{A} 250(10 \mu \mathrm{M})$ and tenapanor $(10 \mu \mathrm{M})$, individually and together, on loop weight/length ratio (top) and luminal $\mathrm{pH}$ (bottom) in mouse distal colonic closed loops (mean \pm SEM, $n=4$ loops per group). (B) Effects of DRA inh $-\mathrm{A} 250$ (10 $\mu \mathrm{M}$ ) and tenapanor $(10 \mu \mathrm{M})$, individually and together, on loop weight/length ratio (top) and luminal pH (bottom) in mouse midjejunal closed loops (mean $\pm \mathrm{SEM}, n=5$-9 loops per group). ${ }^{*} P<0.05$, ${ }^{* *} P<0.01,{ }^{* *} P<0.001$, one-way ANOVA with post-hoc Newman-Keuls multiple comparisons test. $\mathrm{DRA}_{\mathrm{inh}}, \mathrm{DRA}_{\mathrm{inh}}-\mathrm{A} 250$; Ten, tenapanor.

on stool hydration (Figure 7B) (see Discussion and Figure 8 for proposed mechanisms). Importantly, $\mathrm{DRA}_{\text {inh }}-\mathrm{A} 250$ was also effective in a loperamide-induced constipation model in CF mice having loss of function of the prosecretory $\mathrm{Cl}^{-}$channel CFTR (Figure 7C). To study reversibility in vivo, WT mice were treated with DRA ${ }_{\text {inh }}-\mathrm{A} 250$ as in Figure 7A, and loperamide was administered at 24 hours. The loperamide effect was similar to that in mice without preexposure to DRA $\mathrm{inh}_{\text {inh }}-\mathrm{A} 250$ (stool weight $15 \pm 5$ $\mathrm{mg}$, pellet number $1.5 \pm 0.6$, stool water content $31 \% \pm 4 \%$, mean \pm SEM, $n=4$ mice). The anticonstipation effect of DRA $\mathrm{inh}_{\mathrm{in}}-\mathrm{A} 250$ is, thus, not the consequence of a toxic effect on the gastrointestinal tract.

\section{Discussion}

The goal of this study was to identify potent and selective small molecule inhibitors of slc26a 3 in order to test their utility for treatment of constipation and to investigate the role of slc26a3 in intestinal fluid absorption. High-throughput screening identified several classes of slc26a3 inhibitors, which - following structure-activity analysis and optimization - produced the 4,8-dimethylcoumarin $\mathrm{DRA}_{\text {inh }}-\mathrm{A} 250$ with an $\mathrm{IC}_{50}$ of $100-200 \mathrm{nM}$ for inhibition of slc26a3-mediated anion exchange. Importantly, DRA inh $_{\text {in }}$-A250 did not inhibit homologous slc26a-family anion exchangers or relevant intestinal transporters, and it was nontoxic in cell culture (Supplemental Figure 2). Studies in mice demonstrated DRA $_{\text {inh }}$-A250 efficacy in a loperamide model of constipation and provided novel data that clarified the mechanisms of intestinal fluid absorption.

Constipation is a common problem, with an estimated prevalence of $\sim 15 \%$ in the US population (28, 29). The most common types of chronic constipation include chronic idiopathic constipation (CIC), OIC, and constipation-predominant irritable bowel syndrome (IBS-C). Current treatment approaches for chronic constipation include lifestyle and dietary changes, over-the-counter laxatives (e.g., stimulants of intestinal contraction, osmotic agents), and recently approved prescription drugs that promote intestinal fluid secretion 
A

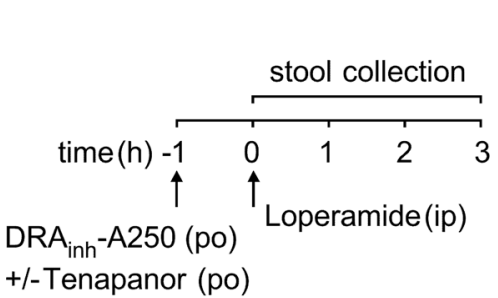

\section{Cystic Fibrosis mice}

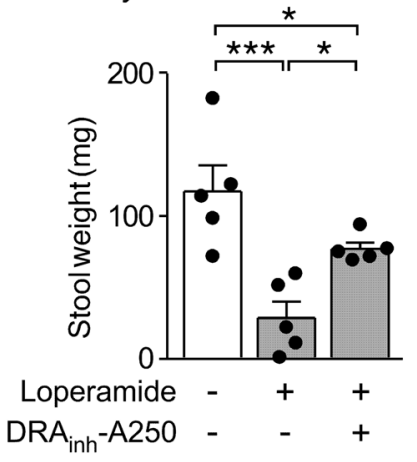

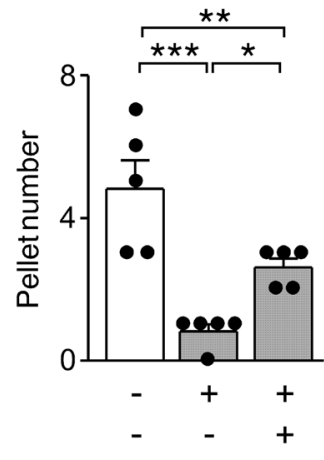

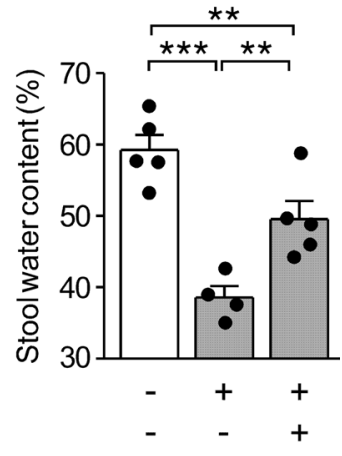

\section{B Wild-type mice}
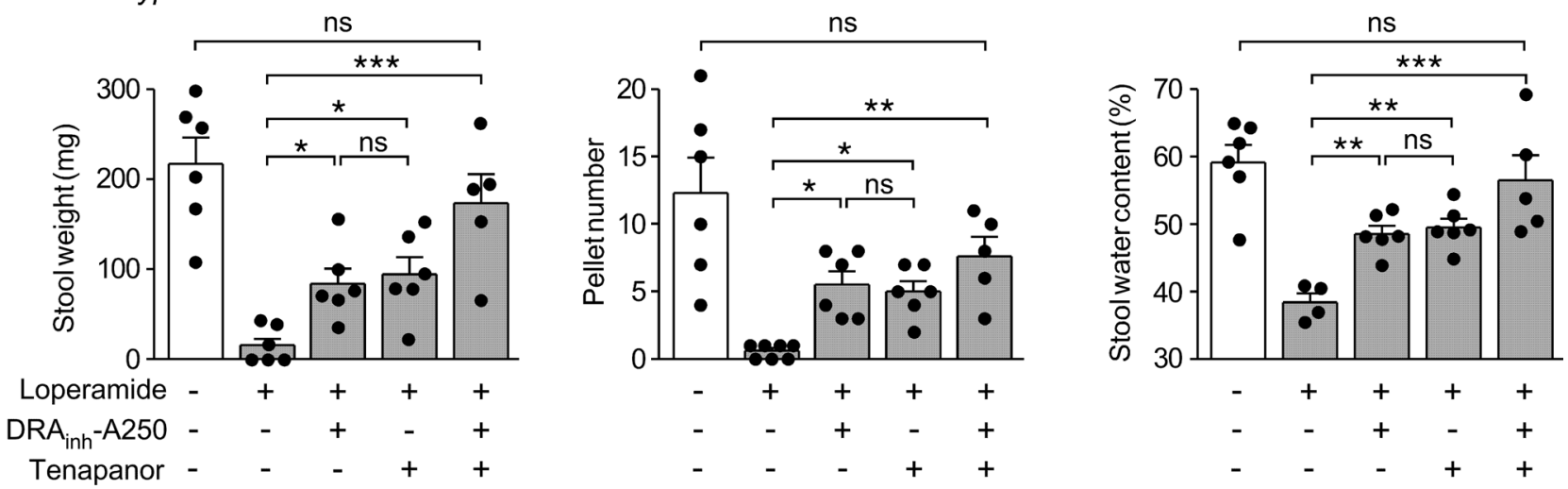

Figure 7. Oral DRA inh -A250 reduces loperamide-induced constipation in WT and cystic fibrosis mice. (A) Mouse model of constipation produced by loperamide. (B) Effects of $\mathrm{DRA}_{\mathrm{inh}}-\mathrm{A} 250(5 \mathrm{mg} / \mathrm{kg})$ and tenapanor $(5 \mathrm{mg} / \mathrm{kg})$, individually and together, on 3-hour stool weight, number of pellets, and stool water content in loperamide-treated WT mice (mean \pm SEM, $n=4-7$ mice per group). Vehicle control shown for comparison. (C) Study as in $A$ done in cystic fibrosis mice lacking functional CFTR (mean \pm SEM, $n=4-5$ mice per group). ${ }^{*} P<0.05,{ }^{*} P<0.01,{ }^{* *} P<0.001$, one-way ANOVA with post-hoc Newman-Keuls multiple comparisons test.

(28-30). Three prosecretory drugs that activate $\mathrm{Cl}^{-}$channels have been approved: lubiprostone, a prostaglandin derivative that indirectly activates CFTR and chloride channel 2 (ClC-2); linaclotide, a peptide agonist of the guanylate cyclase $\mathrm{C}$ receptor that indirectly activates CFTR; and plecanatide, a uroguanylin analog that also acts as an agonist of the guanylate cyclase $\mathrm{C}$ receptor (30). Our group recently reported CFTR activators with marked pro-secretory action and improved efficacy over lubiprostone and linaclotide in experimental animal models of constipation $(26,27,31)$.

Inhibition of intestinal fluid absorption represents an alternative approach to increase stool hydration in constipation. Recent evaluation of the NHE3 inhibitor tenapanor in a Phase 3 clinical trial for IBS-C showed limited efficacy, with $27 \%$ combined pain and stool pattern response rate for the treated group versus $18.7 \%$ for placebo (30). NHE3 is expressed in the small intestine and proximal colon, but not in distal colon $(12,32)$. The limited clinical efficacy of NHE3 inhibition for constipation might be due to unimpaired downstream fluid absorption in the distal colon. As an alternative antiabsorptive approach, we targeted SLC26A3, the major $\mathrm{Cl}^{-} / \mathrm{HCO}_{3}{ }^{-}$exchanger in the colon, and demonstrated comparable efficacy to tenapanor in a murine model of constipation. Theoretically, SLC26A3 inhibition might be more effective than NHE3 inhibition for constipation therapy, as it blocks absorption in the distal colon where stool is dehydrated to its final form. Remarkably, we found additive actions of NHE3 and slc26a3 inhibitors in preventing loperamide-induced constipation. Our results suggest the efficacy of SLC26A3 inhibitors alone for various types of constipation and their combination with tenapanor in patients that do not respond adequately to monotherapy.

In CF subjects, gastrointestinal-related problems are common, including meconium ileus $(\sim 15 \%$ occurrence in neonates), constipation (up to $47 \%$ lifetime prevalence), and distal intestinal obstructive syndrome ( $\sim 15 \%$ lifetime prevalence) $(17,33)$. Impaired function of the prosecretory $\mathrm{CFTR} \mathrm{Cl}^{-}$channel is believed to be the cause of these disorders. We showed previously that an orally administered 
A Jejunum

Lumen

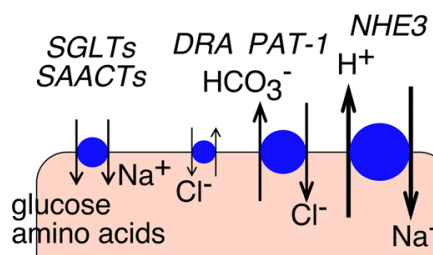

amino acids
Distal colon

\section{Lumen}

DRA ENaC

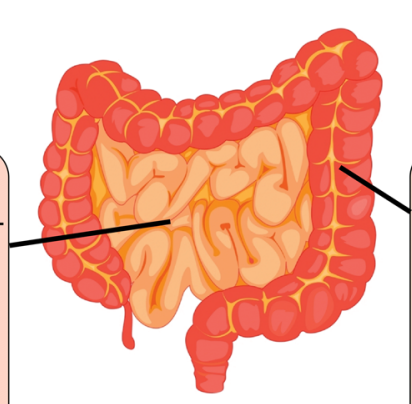

$2 \mathrm{~K}^{+}$

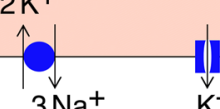

$3 \mathrm{Na}^{+} \quad \mathrm{K}^{+}$

$\begin{array}{ll}\mathrm{Na}^{+-K^{+}} & \mathrm{K}^{+} \text {channel } \\ \text { ATPase } & \end{array}$

ATPase

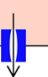

Blood

\section{$\mathrm{HCO}_{3}{ }^{-}$}
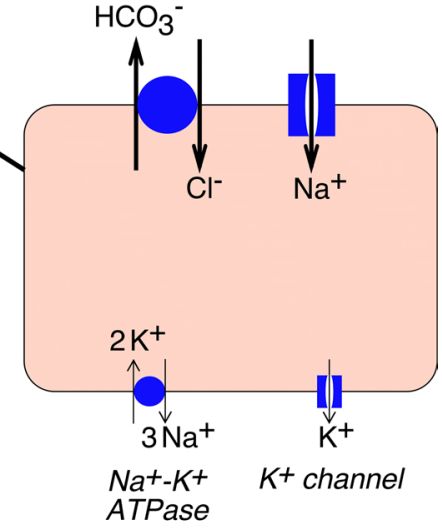

Blood
Figure 8. Intestinal absorption

pathways. (A) Absorptive mechanisms in jejunum and distal colon. Arrow size denotes relative importance in fluid absorption. (B) Proposed sites of actions and mechanism for DRA $_{\text {inh }}$-A250 and tenapanor. Upward black arrows represent absorption, and size and thickness of brown arrows represent hydration of luminal content and stool output. SGLTs, $\mathrm{Na}^{+}$-glucose transporters; SAACTs, $\mathrm{Na}^{+}$-amino acid cotransporters; DRA, downregulated in adenoma (SIc26a3); PAT-1, putative anion transporter-1 (SIc26a6); NHE3, $\mathrm{Na}^{+} / \mathrm{H}^{+}$exchanger 3; $\mathrm{ENaC}$, epithelial sodium channel.

B

Jejunum
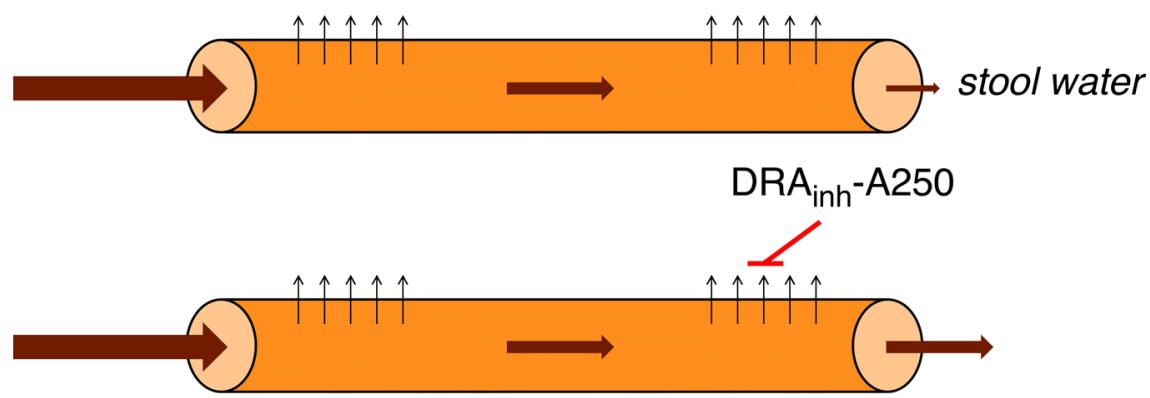

Tenapanor
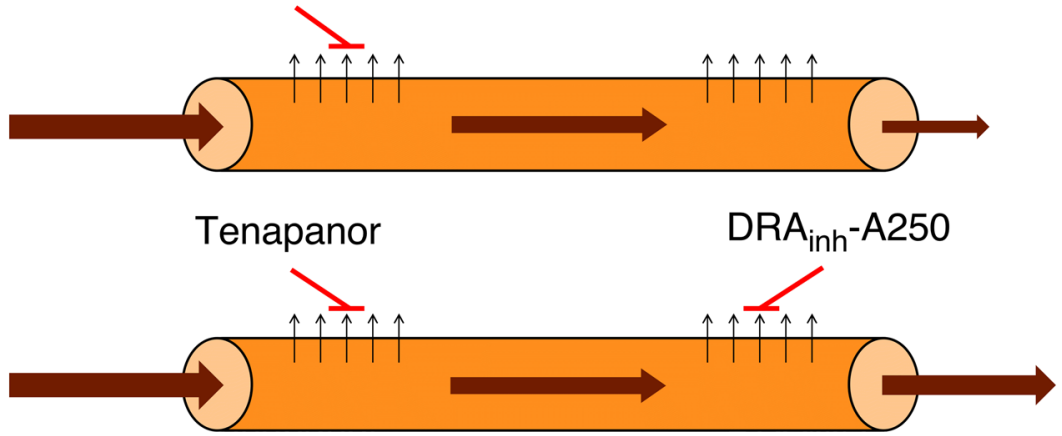

CFTR activator was effective in experimental mouse models of constipation, and - as expected CFTR activation was ineffective in CF mice lacking functional CFTR (26). Here, we demonstrated efficacy of a slc26a3 inhibitor in CF mice in a loperamide model of constipation, which supports the conclusion that intestinal slc26a3 function is not impaired in CF. SLC26A3 inhibition therapy may, thus, be beneficial in promoting stool hydration and treating constipation in human CF subjects - and potentially in preventing or treating meconium ileus in the neonatal period.

There are at least 3 pathways for absorption of $\mathrm{Na}^{+}$and $\mathrm{Cl}^{-}$in the intestine: nutrient-coupled $\mathrm{Na}^{+}$ absorption, electroneutral $\mathrm{NaCl}$ absorption, and electrogenic $\mathrm{Na}^{+}$absorption (13). Nutrient-coupled $\mathrm{Na}^{+}$ absorption in the small intestine involves sodium-glucose transporters (SGLTs) and Na-amino acid cotransporters in which $\mathrm{Cl}^{-}$is absorbed through a paracellular pathway. Electroneutral $\mathrm{NaCl}$ absorption in the small intestine and proximal colon involves $\mathrm{Na}^{+} / \mathrm{H}^{+}$exchangers (NHE2/SLC9A2 and NHE3) and $\mathrm{Cl}^{-} /$ $\mathrm{HCO}_{3}^{-}$exchangers (SLC26A3 and SLC26A6), which are thought to function in tandem to absorb $\mathrm{NaCl}$. 
Electrogenic $\mathrm{Na}^{+}$absorption in the distal colon involves ENaC. The major absorptive pathways in the jejunum and distal colon are diagrammed in Figure 8A. NHE3 and NHE2 are expressed in the small intestine and proximal colon; NHE3 (SLC9A3) is the dominant $\mathrm{Na}^{+} / \mathrm{H}^{+}$exchanger, as it can compensate for loss of NHE2 (34). SLC9A3 mutations cause congenital $\mathrm{Na}^{+}$diarrhea with mild metabolic acidosis, and slc9a3-1mice have mild diarrhea with luminal fluid alkalinization (35). However, compensatory increased ENaC activity in the distal colon of $s l c 9 a 3^{-/-}$mice is thought to limit the severity of diarrhea. SLC26A3 is mainly expressed in the distal colon and duodenum, with low expression in the jejenum and ileum $(3,4)$, whereas SLC26A6 is mainly expressed in the small intestine (36). In agreement with these findings, we found - in mouse jejunum - that slc26a3 inhibition had no effect, while NHE3 inhibition blocked fluid absorption, whereas - in mouse distal colon - slc26a3 inhibition blocked absorption while NHE3 inhibitor had no effect. These results provide pharmacological evidence that slc26a3 plays little or no role in $\mathrm{NaCl}$ absorption in murine small intestine where Slc26a6 is likely the dominant $\mathrm{Cl}^{-} / \mathrm{HCO}_{3}^{-}$exchanger, in agreement with earlier studies $(36,37)$.

Though much of the current understanding of intestinal $\mathrm{NaCl}$ absorption comes from studies using $\mathrm{KO}$ mice, it is recognized that $\mathrm{KO}$ mice can produce confounding secondary phenotypes because of altered gene expression patterns or organ development. For example, with slc26a4 (pendrin), we found remarkable differences in renal physiology with pharmacological inhibition, as compared with slc26a4 ${ }^{-1-}$ mice (20). SLC26A3 loss of function in humans or KO mice produces CLD with marked diarrhea, whereas the inhibitor studied here had only partial efficacy in a mouse model of constipation. This difference could be due to partial efficacy of the inhibitor or, perhaps more likely, to secondary phenotypes in the KO mouse. Our finding that slc26a3 inhibition blocked fluid absorption only in the distal colon supports the latter possibility, as does the additive effect seen on coadministration of slc26a3 inhibitor and tenapanor. An additional contributing factor may be regulatory interactions among NHE3, Slc26a3, and CFTR that may involve the NHE-regulatory factor (NHERF), SLC26 sulfate transporter antisigma (STAS) domain, and the CFTR regulatory domain (13). As many CLD-associated SLC26A3 mutations occur in the STAS domain, the severe CLD phenotype might be a consequence of both the loss of SLC26A3 absorption and dysregulation

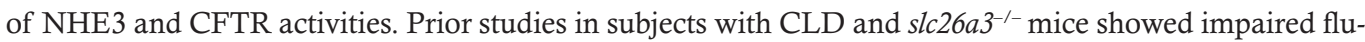
id absorption in the jejunum $(4,38)$, whereas closed-loop studies here suggested that slc26a3 is of minimal importance in fluid absorption in this segment. Further studies will be required to test these ideas.

The closed-loop method used in Figure 6 to measure intestinal fluid absorption is an extension of the commonly used closed-loop method to measure intestinal fluid secretion in which fluid transport is deduced from the weight/length ratio of closed intestinal loops at a specified time after fluid injection. Compared with the conventional method involving in vivo intestinal perfusion and use of a volume marker to deduce fluid transport, the closed-loop method is technically more simple and robust, and it provides data with relatively low variance. Validation studies reported in Supplemental Figure 1 show the expected effect of sodium and chloride ion substitution in preventing fluid absorption, and the expected effect of glucose in increasing fluid absorption in jejunum. We note that use of this method requires an initial time course study to select an appropriate time window and, for quantitation of absolute fluid transport rates, determination of the relationship between loop weight/length ratio and luminal fluid volume.

Though the results here provide proof-of-concept for the therapeutic utility of SLC26A3 inhibition in promoting stool hydration, several caveats are noted. There is a theoretical relationship between SLC26A3 inhibition and tumorigenicity based on the original findings of SLC26A3 downregulation in adenoma and manifestation of an expanded colonic epithelial proliferative zone and surface mucosal hyperplasia in slc26a3 $3^{-1-}$ mice $(1,10)$. Notably, however, CLD subjects with SLC26A3 mutations do not manifest an increased incidence of gastrointestinal cancers $(39,40)$. Reduced SLC26A3 activity is observed in ulcerative colitis, and single-nucleotide polymorphisms in SLC26A3 may be a risk factor for development of ulcerative colitis $(41,42)$; however, loss of SLC26A3 function does not produce intestinal inflammation, as only $6 \%$ of CLD subjects report symptoms of Crohn's disease or unspecified colitis $(15,40)$. Renal insufficiency is observed in $\sim 25 \%$ of CLD subjects, although this likely results from delayed diagnosis and consequent chronic volume and salt depletion (15). SLC26A3 mutations are also associated with male subfertility, although available evidence suggests that impaired SLC26A3-CFTR interaction and consequent impaired CFTR activity are responsible (43). In general, with appropriate salt-replacement therapy, the long-term health in CLD is good, suggesting the absence of significant tumor and nongastrointestinal problems with SLC26A3 mutation (40). 
There have been a few prior reports on the biological properties of the 7-benzoxy-4,8-dimethyl-3-acetic acid-coumarin scaffold, as found in $\mathrm{DRA}_{\mathrm{inh}}$-A250. Similar coumarins were reported as inhibitors of Bacillus anthracis and Staphylococcus aureus replicative DNA helicase (24). Another 3-acetic acid-coumarin was reported to inhibit the oncogene signal transducer and activator of transcription (Stat3) activation by inhibiting the nuclear translocation of phosphorylated Stat3 (44). In general, coumarins are plant-derived natural products with diverse inflammatory, antitumor, antibacterial, and antifungal properties (45). The physico-chemical properties of $\mathrm{DRA}_{\mathrm{inh}}-\mathrm{A} 250$ include the presence of multiple hydrogen bond acceptors, a molecular mass of $417 \mathrm{Da}$, a logP value of 4.6, and a topologic polar surface area of $73 \AA^{2}$, all of which are consistent with druglike properties, including oral bioavailability. In addition, the 3-acetic-acid-coumarin scaffold does not belong to promiscuous binders known as panassay interference compound molecules. Synthetically, the 3-aceticacid-coumarin scaffold can be prepared in 3-5 steps from commercially available starting materials, which allows facile synthesis of targeted analogs.

In summary, we found that slc26a3 is a druggable target in which small molecule inhibitor therapy may be beneficial for antiabsorptive therapy of the common types of constipation, as well as in constipation associated with CF.

\section{Methods}

Molecular biology. Vectors containing complementary DNA (cDNA) for slc26a3, SLC26A3, slc26a6, and slc26a9 were purchased from Origene and manipulated using standard techniques (see Supplemental Methods). To generate a cell line for screening, slc26a3 was subcloned into pIRESpuro3 (Clontech). Human SLC26A3 was subcloned into pLVX-IRES-mCherry (Clontech), and other slc26 family members were subcloned into vectors that were generated to coexpress the halide sensitive EYFP-H148Q/ I152L/F46L (YFP).

Cell culture and transfections. FRT epithelial cells (UCSF Cell Culture Facility), HEK cells (UCSF Cell Culture Facility), and HBE cell cultures (UCSF Cystic Fibrosis Research Development Program) were cultured using standard methods (19). For slc26a3 inhibitor screening, an FRT cell line virally transduced to express YFP (46) was transfected with pIRESpuro3-slc26a3, selected using $0.15 \mu \mathrm{g} / \mathrm{ml}$ puromycin, and a clonal cell line (termed FRT-YFP-slc26a3) was isolated. To generate a cell line enriched for expression of SLC26A3, HEK293 cells were transduced with lentirival particles generated from the pLVX-IRES-mCherry-SLC26A3 vector and then transfected to express YFP. FRT cells expressing YFP and slc26a4 (pendrin) or CFTR were previously described $(20,26)$. FRT cells were transfected with Lipofectamine 2000 (Thermo Fisher Scientific), and HEK cells were transfected with NanoFect (Alstem).

Screening and synthetic chemistry. High-throughput screening to identify slc26a3 inhibitors using FRT-YFPslc26a3 cells was done with a semiautomated Beckman Coulter platform with FLUOstar OMEGA plate readers (BMG Labtech), essentially as described for discovery of pendrin inhibitors (19). Initial screening was done of $\sim 50,000$ drug-like synthetic small molecules (ChemDiv) at a concentration of $25 \mu \mathrm{M}$ using a $\mathrm{Cl}^{-} / \mathrm{I}^{-}$ exchange protocol to assay slc26a3 function. Following initial screening, compound analogs were purchased (ChemDiv) to generate structure-activity data. The lead slc26a3 inhibitor was resynthesized and confirmed by ${ }^{1} \mathrm{H}$ and ${ }^{13} \mathrm{C} \mathrm{NMR}$, and $>95 \%$ purity was confirmed by liquid chromatography-mass spectrometry (LC-MS).

Selectivity studies. YFP-based assays of CFTR, pendrin, and TMEM16A were as described (19, 26, 47, 48). HEK cells transfected to express YFP and SLC26A3, slc26a6, or slc26a9 were functionally assayed using a $\mathrm{Cl}^{-} / \mathrm{I}^{-}$exchange protocol. Assays of the $\mathrm{Cl}^{-} / \mathrm{HCO}_{3}{ }^{-}$exchange were done using $\mathrm{BCECF}$ as an intracellular $\mathrm{pH}$ indicator as described for pendrin (19). $\mathrm{I}_{\mathrm{sc}}$ measurements in well-differentiated $\mathrm{HBE}$ cell cultures were done as described (19).

Murine models. Closed-loop models and the loperamide-induced model of constipation were done in mice as described $(26,27)$. Mice were housed and bred in the UCSF Laboratory Animal Resource Center.

Statistics. Details of statistical methods are provided in individual figure legends. One-way ANOVA was used for multiple comparisons, with Newman-Keuls post hoc multiple comparisons test. Student's $t$ test (two-tailed) was used to test significance for comparisons of 2 data sets. $P<0.05$ was considered significant.

Study approval. Animal experiments were approved by the UCSF IACUC. Procurement and use of HBE cell cultures was approved by the UCSF Human Research Protection Program IRB. For further details, see online Supplemental Methods. 


\section{Author contributions}

PMH, OC, SL, JAT, AAR, and PWP performed in vitro and in vivo experiments. PMH, OC, JAT, and PWP analyzed data. PMH, OC, SL, and ASV designed experiments. PMH, OC, SL, PWP, and ASV wrote the manuscript. PMH and ASV developed the original concept for this study.

\section{Acknowledgments}

This work was supported by grants from the NIH (DK099803, DK72517, DK101373, EY13573), Cystic Fibrosis Foundation (R613), and Cystic Fibrosis Research Incorporated (New Horizons Research). The authors thank Lorna Zlock and Walter E. Finkbeiner for providing HBE cultures, and Mark Donowitz for helpful discussions.

Address correspondence to: Alan S. Verkman or Peter M. Haggie, 1246 Health Science East Tower, 513 Parnassus Avenue, University of California, San Francisco, San Francisco, California, 94143-0521, USA. Phone: 415.476.8530; Email: Alan.Verkman@ucsf.edu (A.S. Verkman); Peter.Haggie@ucsf.edu (P.M. Haggie).

1. Schweinfest CW, Henderson KW, Suster S, Kondoh N, Papas TS. Identification of a colon mucosa gene that is down-regulated in colon adenomas and adenocarcinomas. Proc Natl Acad Sci USA. 1993;90(9):4166-4170.

2. Byeon MK, et al. The down-regulated in adenoma (DRA) gene encodes an intestine-specific membrane glycoprotein. Oncogene. 1996;12(2):387-396

3. Höglund P, et al. Mutations of the Down-regulated in adenoma (DRA) gene cause congenital chloride diarrhoea. Nat Genet. 1996;14(3):316-319.

4. Walker NM, et al. Down-regulated in adenoma $\mathrm{Cl} / \mathrm{HCO} 3$ exchanger couples with $\mathrm{Na} / \mathrm{H}$ exchanger $3 \mathrm{for} \mathrm{NaCl}$ absorption in murine small intestine. Gastroenterology. 2008;135(5):1645-1653.e3.

5. Shcheynikov $\mathrm{N}$, et al. Coupling modes and stoichiometry of $\mathrm{Cl}^{-} / \mathrm{HCO}_{3}^{-}$exchange by slc26a3 and slc26a6. J Gen Physiol. 2006;127(5):511-524

6. Dorwart MR, Shcheynikov N, Yang D, Muallem S. The solute carrier 26 family of proteins in epithelial ion transport. Physiology (Bethesda). 2008;23:104-114.

7. Ohana E, Yang D, Shcheynikov N, Muallem S. Diverse transport modes by the solute carrier 26 family of anion transporters J Physiol (Lond). 2009;587(Pt 10):2179-2185.

8. Alper SL, et al. Native and recombinant Slc26a3 (downregulated in adenoma, Dra) do not exhibit properties of $2 \mathrm{Cl}^{-} / 1 \mathrm{HCO}_{3}{ }^{-}$ exchange. Am J Physiol, Cell Physiol. 2011;300(2):C276-C286.

9. Alper SL, Sharma AK. The SLC26 gene family of anion transporters and channels. Mol Aspects Med. 2013;34(2-3):494-515.

10. Schweinfest CW, et al. slc26a3 (dra)-deficient mice display chloride-losing diarrhea, enhanced colonic proliferation, and distinct up-regulation of ion transporters in the colon. J Biol Chem. 2006;281(49):37962-37971.

11. Walker NM, et al. Role of down-regulated in adenoma anion exchanger in $\mathrm{HCO}_{3}^{-}$secretion across murine duodenum. Gastroenterology. 2009;136(3):893-901.

12. Talbot C, Lytle C. Segregation of Na/H exchanger-3 and $\mathrm{Cl} / \mathrm{HCO} 3$ exchanger SLC26A3 (DRA) in rodent cecum and colon. Am J Physiol Gastrointest Liver Physiol. 2010;299(2):G358-G367.

13. Kato A, Romero MF. Regulation of electroneutral NaCl absorption by the small intestine. Annu Rev Physiol. 2011;73:261-281.

14. Xiao F, et al. Slc26a3 deficiency is associated with loss of colonic $\mathrm{HCO}_{3}^{-}$secretion, absence of a firm mucus layer and barrier impairment in mice. Acta Physiol (Oxf). 2014;211(1):161-175.

15. Wedenoja S, Höglund P, Holmberg C. Review article: the clinical management of congenital chloride diarrhoea. Aliment Phar macol Ther. 2010;31(4):477-485.

16. Wedenoja S, Pekansaari E, Höglund P, Mäkelä S, Holmberg C, Kere J. Update on SLC26A3 mutations in congenital chloride diarrhea. Hum Mutat. 2011;32(7):715-722.

17. van der Doef HP, Kokke FT, van der Ent CK, Houwen RH. Intestinal obstruction syndromes in cystic fibrosis: meconium ileus, distal intestinal obstruction syndrome, and constipation. Curr Gastroenterol Rep. 2011;13(3):265-270.

18. Wall SM, Lazo-Fernandez Y. The role of pendrin in renal physiology. Annu Rev Physiol. 2015;77:363-378.

19. Haggie PM, Phuan PW, Tan JA, Zlock L, Finkbeiner WE, Verkman AS. Inhibitors of pendrin anion exchange identified in a small molecule screen increase airway surface liquid volume in cystic fibrosis. FASEB J. 2016;30(6):2187-2197.

20. Cil O, Haggie PM, Phuan PW, Tan JA, Verkman AS. Small-molecule inhibitors of pendrin potentiate the diuretic action of furosemide. J Am Soc Nephrol. 2016;27(12):3706-3714.

21. Simpson JE, et al. PAT-1 (Slc26a6) is the predominant apical membrane $\mathrm{Cl}^{-} / \mathrm{HCO}_{3}^{-}$exchanger in the upper villous epithelium of the murine duodenum. Am J Physiol Gastrointest Liver Physiol. 2007;292(4):G1079-G1088.

22. Walker NM, et al. Functional activity of Pat-1 (Slc26a6) $\mathrm{Cl}^{-} / \mathrm{HCO}_{3}{ }^{-}$exchange in the lower villus epithelium of murine duodenum. Acta Physiol (Oxf). 2011;201(1):21-31.

23. Garazd MM, Garazd YL, Khilya VP. Neoflavines. 2. Methods for synthesizing and modifying 4-arylcoumarins. Chem Nat Compd. 2005;41(3):245-271.

24. Li B, et al. Coumarin-based inhibitors of Bacillus anthracis and Staphylococcus aureus replicative DNA helicase: chemical optimization, biological evaluation, and antibacterial activities. J Med Chem. 2012;55(24):10896-10908.

25. Chey WD, Lembo AJ, Rosenbaum DP. Tenapanor treatment of patients with constipation-predominant irritable bowel syndrome: A phase 2, randomized, placebo-controlled efficacy and safety Trial. Am J Gastroenterol. 2017;112(5):763-774. 
26. Cil O, et al. CFTR activator increases intestinal fluid secretion and normalizes stool output in a mouse model of constipation. Cell Mol Gastroenterol Hepatol. 2016;2(3):317-327.

27. Cil O, et al. Phenylquinoxalinone CFTR activator as potential prosecretory therapy for constipation. Transl Res. 2017;182:14-26.e4

28. Rao SS, Rattanakovit K, Patcharatrakul T. Diagnosis and management of chronic constipation in adults. Nat Rev Gastroenterol Hepatol. 2016;13(5):295-305.

29. Camilleri M, et al. Chronic constipation. Nat Rev Dis Primers. 2017;3:17095.

30. Bharucha AE, Wouters MM, Tack J. Existing and emerging therapies for managing constipation and diarrhea. Curr Opin Pharmacol. 2017;37:158-166.

31. Son JH, et al. High-potency phenylquinoxalinone cystic fibrosis transmembrane conductance regulator (CFTR) activators J Med Chem. 2017;60(6):2401-2410.

32. Magalhães D, Cabral JM, Soares-da-Silva P, Magro F. Role of epithelial ion transports in inflammatory bowel disease. Am J Physiol Gastrointest Liver Physiol. 2016;310(7):G460-G476.

33. Sabharwal S. Gastrointestinal manifestations of cystic fibrosis. Gastroenterol Hepatol (N Y). 2016;12(1):43-47.

34. Ledoussal C, Woo AL, Miller ML, Shull GE. Loss of the NHE2 $\mathrm{Na}(+) / \mathrm{H}(+)$ exchanger has no apparent effect on diarrheal state of NHE3-deficient mice. Am J Physiol Gastrointest Liver Physiol. 2001;281(6):G1385-G1396.

35. Schultheis PJ, et al. Renal and intestinal absorptive defects in mice lacking the NHE3 $\mathrm{Na}^{+} / \mathrm{H}^{+}$exchanger. Nat Genet. 1998;19(3):282-285.

36. Wang Z, Petrovic S, Mann E, Soleimani M. Identification of an apical $\mathrm{Cl}^{-} / \mathrm{HCO}_{3}^{-}$exchanger in the small intestine. Am $J$ Physiol Gastrointest Liver Physiol. 2002;282(3):G573-G579.

37. Seidler U, et al. Sodium and chloride absorptive defects in the small intestine in Slc26a6 null mice. Pflugers Arch. 2008;455(4):757-766

38. Freel RW, Whittamore JM, Hatch M. Transcellular oxalate and $\mathrm{Cl}^{-}$absorption in mouse intestine is mediated by the DRA anion exchanger Slc26a3, and DRA deletion decreases urinary oxalate. Am J Physiol Gastrointest Liver Physiol. 2013;305(7):G520-G527.

39. Hemminki A, et al. Intestinal cancer in patients with a germline mutation in the down-regulated in adenoma (DRA) gene. Oncogene. 1998;16(5):681-684.

40. Hihnala S, Höglund P, Lammi L, Kokkonen J, Ormälä T, Holmberg C. Long-term clinical outcome in patients with congenital chloride diarrhea. J Pediatr Gastroenterol Nutr. 2006;42(4):369-375.

41. Asano K, et al. A genome-wide association study identifies three new susceptibility loci for ulcerative colitis in the Japanese population. Nat Genet. 2009;41(12):1325-1329.

42. Priyamvada S, Gomes R, Gill RK, Saksena S, Alrefai WA, Dudeja PK. Mechanisms underlying dysregulation of electrolyte absorption in inflammatory bowel disease-associated diarrhea. Inflamm Bowel Dis. 2015;21(12):2926-2935.

43. Wedenoja S, et al. A missense mutation in SLC26A3 is associated with human male subfertility and impaired activation of CFTR. Sci Rep. 2017;7(1):14208

44. Xu X, Kasembeli MM, Jiang X, Tweardy BJ, Tweardy DJ. Chemical probes that competitively and selectively inhibit Stat3 activation. PLoS One. 2009;4(3):e4783.

45. Venugopala KN, Rashmi V, Odhav B. Review on natural coumarin lead compounds for their pharmacological activity. Biomed Res Int. 2013;2013:963248.

46. Haggie PM, et al. Correctors and potentiators rescue function of the truncated W1282X-cystic fibrosis transmembrane regulator (CFTR) translation product. J Biol Chem. 2017;292(3):771-785.

47. Ma T, et al. Thiazolidinone CFTR inhibitor identified by high-throughput screening blocks cholera toxin-induced intestinal fluid secretion. J Clin Invest. 2002;110(11):1651-1658.

48. Namkung W, Phuan PW, Verkman AS. TMEM16A inhibitors reveal TMEM16A as a minor component of calcium-activated chloride channel conductance in airway and intestinal epithelial cells. J Biol Chem. 2011;286(3):2365-2374. 